\title{
ANÁLISE DA MARGEM DE DISCRICIONARIEDADE NO ORÇAMENTO DO MUNICÍPIO DE TEÓFILO OTONI-MG.
}

\section{ANALYSIS OF THE MARGIN OF DISCRICIONARIETY IN PUBLIC MANAGEMENT: CASE STUDY OF THE MUNICIPALITY OF TEÓFILO OTONI.}

\section{Marcélia Aguiar Ferreira}

Administradora, Especialista em Comunicação, Marketing e $\mathrm{RH}$, Coordenadora e Prof ${ }^{\mathrm{a}}$. Titular do Curso de Administração da Universidade Presidente Antônio Carlos UNIPACTO -

E-mail: marceliaaguiar@hotmail.com

\section{Adriana Aparecida da Conceição Santos Sá}

Doutoranda do Programa de Pós-graduação Interdisciplinar em Ciências Humanas da Universidade Federal de Santa Catarina (PPGICH/UFSC). Mestre em Gestão Integrada do Território pela Universidade Vale do Rio Doce - UNIVALE (2014). Especialista em Gestão de

Micro e Pequenas Empresas pela Universidade Federal de Lavras - UFLA (2005).

Professora Assistente da Universidade Federal dos Vales do Jequitinhonha e Mucuri

(UFVJM - Campus do Mucuri) e-mail: admpublica@ead.ufvjm.edu.br

\section{Resumo}

Esse trabalho tem como objetivo fazer uma análise da margem de discricionariedade no orçamento do município de Teófilo Otoni- MG, no período de 2013 a 2016, no que se refere à composição orçamentária vinculada, em termos das principais fontes de receita e despesas, da classificação por finalidade e por natureza do gasto. Foram analisadas as receitas e despesas vinculadas com base na Lei de Responsabilidade Fiscal - LRF. Trata-se de uma pesquisa descritiva de natureza quantitativa e qualitativa, realizada por meio de dados coletados junto à TCE/MG - Tribunal de Contas do Estado de Minas gerais. Os resultados encontrados serão analisados e descritos em percentuais para que seja apresentado o quanto as receitas e despesas vinculadas representam do total da Receita Corrente Líquida desse município.

Palavras-chave: Discricionaridade, Vinculação, Orçamento, Teófilo Otoni.

\section{Abstract}

This work intends to make an analysis of the margin of discretion in the public management: case study of the municipality of TeófiloOtoni- MG. The present study analyzes the budget profile of the Municipality of TeófiloOtoni - MG, in the period from 2013 to 2016, in relation to the budget composition linked, in terms of the main 
sources of income and expenses, classification by purpose and nature of expenditure. The income and expenses were analyzed based on the Fiscal Responsibility Law - LRF. This is a descriptive research of a quantitative and qualitative nature, carried out by means of data collected from the TCE / MG - Court of Accounts of the State of Minas Gerais. The results will be analyzed and described in percentages to show how much the related revenues and expenses represent the total of the collection of this municipality.

Keys-word: Discretionary, Linking, Budget, Teófilo Otoni

\section{Introdução}

A vinculação orçamentária apresenta-se como um tema preponderante, quando se analisa o cenário da Gestão Pública para União, Estados e Municípios.

Em um cenário de recursos financeiros tão escassos como o atual. Cabe ao Estado garantir a segurança, justiça e o bem-estar econômico e social, fundamentado na Constituição Federal de 1988. Aos entes públicos, convém promover políticas que propiciem o equilíbrio a paz social, gerenciando a administração pública e aplicação dos recursos públicos em ações que satisfaçam as necessidades coletivas sociais. Procurando equilibrar o mercado e garantir o seu bom funcionamento, fazendo com que a economia do país cresça.

Para Vieira (2007, p.22), a Constituição de 1988 aponta para um Estado Social e Democrático de Direito, que tem um caráter inovador, que busca traçar novos horizontes à administração pública brasileira. Entende-se que a administração pública democrática e participativa é o modelo mais adequado que atenderá as necessidades da sociedade atual. Entende-se que a Constituição Federal de 1988, além de traçar rumos ao modelo de Estado e ao modelo de administração, inaugura os novos direitos e, portanto, novas políticas públicas para o Estado e a coletividade.

Torres (2012), afirma que é preocupante a situação da administração pública municipal: pela excessiva baixa qualidade profissional da burocracia; pelo estrangulamento orçamentário e fiscal desse ente federativo e também pela reduzida capacidade da comunidade local de se mobilizar e efetivamente controlar a administração municipal.

De acordo com Tavares (2015), a reforma do Estado, no Mundo e no Brasil, está na linha do aperfeiçoamento institucional, pois visa proporcionar segurança, educação, saúde, transporte, etc. A atuação do Estado no Brasil, sempre foi decisiva no processo de desenvolvimento científico, econômico, cultural e promocional de 
interações entre os indivíduos. O autor acima não admite que uma reforma se dê somente no aspecto econômico, mas que seja uma reforma em que o cidadão seja certificado das ações do Estado na sociedade.

Ainda segundo Tavares (2015), a Reforma Gerencial trouxe uma nova perspectiva em relação ao cidadão, transformando-o e reconhecendo-o como principal beneficiário das ações do Estado. A ênfase na participação representa o envolvimento de todos os servidores na melhoria do serviço público, e no compromisso de cooperação entre gerentes e gerenciados para o aperfeiçoamento contínuo, buscando assim a satisfação do cidadão, foi adotado como instrumento de reforma da administração pública brasileira, que levou em conta a dimensão política para levar as organizações públicas a atender as necessidades dos cidadãos-cliente.

Nesse contexto de vinculação de receitas públicas em orçamento público, que o presente estudo traz como problematização: uma análise da margem de discricionariedade no orçamento do município de Teófilo Otoni.

O município de Teófilo Otoni tem uma população total 134.745 mil habitantes, com base nos dados do censo 2010, do IBGE. Teófilo Otoni possui área territorial de $3.242,270 \mathrm{Km}^{2}$, densidade demográfica de 41,56 habitantes $\mathrm{km}^{2}$, é a décima sétima cidade mais populosa do Estado de Minas Gerais. Com o PIB de $\mathrm{R} \$ 1.377 .301$ reais, e o PIB per capita $R \$ 10.190,60$ reais conforme os últimos dados do IBGE ano de 2011.

Localizado no nordeste do estado de Minas Gerais, no vale do rio Mucuri, é considerado o centro macrorregional, fundada em 07/09/1853, recebeu este nome em homenagem ao fundador da cidade Teophilo Benedito Otoni, sua emancipação foi em 09/11/1878 (criação do município), com topografia montanhosa, está a 349 metros de altitude, no Nordeste de Minas Gerais.

\section{REFERENCIAL TEÓRICO}

\subsection{A discricionariedade no contexto do Federalismo Brasileiro}

O tema da discricionariedade dos atos da Administração Pública é tormentoso e amplo, sendo que a doutrina jurídica já a adotou como critério para a classificação dos atos administrativos. Isso por si demonstra a sua influência fundamental ao se tratar de Administração Pública, já que determinadas atuações 
administrativas apenas podem se dar mediante um exercício discricionário (ANJOS, 2017).

Ainda segundo Anjos (2017), o conceito clássico de discricionariedade reside no âmbito da liberdade concedida pelo legislador ao administrador a fim de que esse exercite determinados poderes e expeça determinados atos, em situações de conceitos jurídicos indeterminados, cláusulas abertas e situações cujas circunstâncias são tão específicas que a Lei não pode se arvorar em dizer, desde logo, os parâmetros de atuação.

Os atos de despesa pública são atos administrativos. Emanados do executivo, constituem a execução concreta do Orçamento, recebendo, autorizando e proporcionando a saída de recursos através do empenho e da liquidação, além de determinar, quando cabível, a execução de um projeto pelos funcionários subordinados (ANJOS, 2017).

Assim, segundo Anjos (2017), é inegável a necessidade de existência da discricionariedade quando da execução do orçamento, face à própria otimização de atos e resultados sociais, não podendo um documento legal ser considerado como um fim em si mesmo, indiferente às condições materiais de existência das relações da vida. No entanto, não se pode ir ao outro extremo, como apregoam muitos, de se considerar a Lei Orçamentária como mero ato formal dotado de nenhuma força normativa (vinculativa), sob 0 argumento de que há discricionariedade administrativa.

De acordo com Anjos (2017), no que tange ao ato discricionário de despesa, identifica-se, segundo a ordem constitucional vigente, a discricionariedade em dois momentos distintos. O primeiro se refere à iniciativa da Lei Orçamentária, quando, após ter se debruçado no plano de governo, o administrador elege as necessidades que devam ser satisfeitas prioritariamente. A regra é a discricionariedade no planejamento e na execução do Orçamento Público (com a aprovação do Legislativo, enfatize-se), sendo que esse constitui a gerência do dinheiro público pelo Administrador, como pressuposto à consecução de políticas públicas. Logo, a discricionariedade nessa esfera deve ser amplamente estudada, com o fito de verificar a própria legitimidade da atuação do Poder Público nesse setor, qual seja, orçamentário e de políticas públicas.

No contexto federativo brasileiro, conhecer a disponibilidade de recursos financeiros e o perfil das despesas dos municípios é de fundamental relevância para 
identificação de problemas e levantamento de soluções que integrem a atuação dos poderes municipais, estaduais, federal. Isto é igualmente importante para sociedade. É uma forma de sobretudo, oportunizar a conscientização fiscal, subsidiar o controle social e promover o exercício da cidadania, face aos instrumentos de planejamento e gestão social.

Segundo Sostemeier (2012), o Orçamento Público é o meio de planejamento das finanças públicas, constituindo-se pelas receitas e despesas públicas. A lei 4.320 de 1.964 estabeleceu a organização das finanças públicas para os órgãos públicos. No âmbito das Finanças Públicas, o orçamento tem a função de nortear as atividades do governo nas três esferas, bem como autarquias e empresas públicas. A lei complementar 101, de 2000, também chamada Lei de Responsabilidade Fiscal - LRF impõe maior responsabilidade aos gastos dos recursos públicos, ao estabelecer limites para alguns gastos e indicadores de gestão. Associado a isso, a autora destaca a importância da gestão pública profissional, capacitada para planejar e gerir os recursos públicos.

A Constituição Federal de 1988 (CRFB/1988) reconheceu os municípios como entes da federação e assegurou sua autonomia política, administrativa e fiscal. No âmbito da autonomia político-administrativa ficou assegurada a sua administração própria no que se refere aos assuntos de interesses locais, de modo específico, em relação aos tributos e à organização dos serviços públicos (REZENDE, 2006).

Para Souza (2004) as políticas voltadas para a municipalização não foram impulsionadas pela vontade de proporcionar a descentralização administrativa, e sim por uma questão eminentemente política. Nesse contexto, identificam-se alguns fatores que contribuíram para a emancipação de novos municípios.

O primeiro, relativo à arrecadação, com a possibilidade de compartilhamento dos Fundos de Participação entre as unidades novas e antigas; o segundo, de natureza política, já que essas mudanças possibilitariam não apenas o surgimento de lideranças locais, mas também a acomodação de grupos rivais, resultando em um novo formato de repartição do poder político administrativo. Outro aspecto é que a opção pela fragmentação se tornou uma forma de simplificação da gestão por meio de soluções locais (REIS; COSTA; SILVEIRA, 2013, p. 67).

Para Tomio (2002), a garantia de repasse do Fundo de Participação dos Municípios - FPM foi uma das principais motivações para emancipação de pequenos municípios, pois parecia ser um grande negócio para as pequenas localidades do interior. Esse autor afirmou que a receita própria desses municípios 
seria incapaz de pagar sequer os cargos políticos criados pela emancipação: prefeitos, vereadores e secretários municipais.

Para Reis; Costa e Silveira (2013) o processo de emancipação municipal resultou na criação de grande número de municípios de pequeno porte, com baixa capacidade de arrecadação tributária, menores transferências do Imposto sobre Circulação de Mercadorias e Serviços - ICMS e forte dependência do Fundo de Participação dos Municípios - FPM.

Diante o exposto, nota-se que as questões relacionadas às fontes de receitas e destino das despesas de pequenos municípios devem ser postas em pauta.

\subsection{Receita Públicas no planejamento orçamentário}

O orçamento é instrumento de planejamento de qualquer entidade, seja pública ou privada, e representa o fluxo previsto dos ingressos e das aplicações de recursos em determinado período. A matéria pertinente à receita é disciplinada, em linhas gerais, pelos arts. $3^{\circ}, 9^{\circ}, 11^{\circ}, 35^{\circ}$ e $57^{\circ}$ da Lei no 4.320, de 1964. Em sentido amplo, receitas públicas são ingressos de recursos financeiros nos cofres do Estado, que se desdobram em receitas orçamentárias, quando representam disponibilidades de recursos financeiros para o erário, e ingressos extra orçamentários, quando representam apenas entradas compensatórias. Em sentido estrito, são públicas apenas as receitas orçamentárias. BRASIL, MTO (2017)

As receitas orçamentárias são disponibilidades de recursos financeiros que ingressam durante o exercício e constituem elemento novo para o patrimônio público. Instrumento por meio do qual se viabiliza a execução das políticas públicas, a receita orçamentária é fonte de recursos utilizada pelo Estado em programas e ações cuja finalidade precípua é atender às necessidades públicas e demandas da sociedade. Essas receitas pertencem ao Estado, integram o patrimônio do Poder Público, aumentam-Ihe o saldo financeiro e, via de regra, por força do princípio da universalidade, estão previstas na LOA. BRASIL, MTO (2017)

Nesse contexto, embora haja obrigatoriedade de a LOA registrar a previsão de arrecadação das receitas, a mera ausência formal desse registro não lhes retira 0 caráter orçamentário, haja vista o art. 57 da Lei no 4.320, de 1964, classificar como receita orçamentária toda receita arrecadada que represente ingresso financeiro orçamentário, inclusive a proveniente de operações de crédito. BRASIL, MTO (2017) 
Segundo descrito no Manual Técnico de Orçamento - MTO (2017), A classificação da receita orçamentária, a exemplo do que ocorre na despesa, é de utilização obrigatória por todos os entes da Federação, sendo facultado o seu desdobramento para atendimento das respectivas necessidades. Sobre o assunto, as receitas orçamentárias são classificadas segundo os seguintes critérios: natureza de receita, indicador de resultado primário, fonte/destinação de recursos e esfera orçamentária.

\subsection{Despesa Públicas na estrutura orçamentária}

A estrutura da programação orçamentária, a compreensão do orçamento exige o conhecimento de sua estrutura e sua organização, implementadas por meio de um sistema de classificação estruturado.

Esse sistema tem o propósito de atender às exigências de informação demandadas por todos os interessados nas questões de finanças públicas, como os poderes públicos, as organizações públicas e privadas e a sociedade em geral. $\mathrm{Na}$ estrutura atual do orçamento público, as programações orçamentárias estão organizadas em programas de trabalho, que contêm informações qualitativas e quantitativas, sejam físicas ou financeiras. BRASIL, MTO (2017)

A programação qualitativa define qualitativamente a programação orçamentária, deve responder, de maneira clara e objetiva, às perguntas clássicas que caracterizam o ato de orçar, sendo, do ponto de vista operacional, composto dos seguintes blocos de informação: classificação por esfera, classificação institucional, classificação funcional, estrutura programática e principais informações do Programa e da Ação. BRASIL, MTO (2017)

A programação orçamentária quantitativa tem duas dimensões: a física e a financeira. A dimensão física define a quantidade de bens e serviços a serem entregues. A dimensão financeira estima o montante necessário para 0 desenvolvimento da ação orçamentária. BRASIL, MTO (2017)

A classificação da despesa por esfera orçamentária está na LOA, a esfera tem por finalidade identificar se a despesa pertence ao Orçamento Fiscal $(F)$, da Seguridade Social (S) ou de Investimento das Empresas Estatais (I), conforme disposto no $\S 5^{\circ}$ do art. 165 da CF. Na LOA, o classificador de esfera é identificado com as letras "F", "S" ou "I", na base de dados do SIOP.BRASIL, MTO (2017) 
A classificação funcional é formada por funções e subfunções e busca responder basicamente à indagação "em que áreas de despesa a ação governamental será realizada?". Cada atividade, projeto e operação especial identificarão a função e a subfunção às quais se vinculam.

A atual classificação funcional foi instituída pela Portaria № 42, de 14 de abril de 1999, do então Ministério do Orçamento e Gestão (MOG), e é composta de um rol de funções e subfunções prefixadas, que servem como agregador dos gastos públicos por área de ação governamental nos três níveis de Governo. Trata-se de uma classificação independente dos programas e de aplicação comum e obrigatória, no âmbito dos Municípios, dos Estados, do Distrito Federal e da União, o que permite a consolidação nacional dos gastos do setor público. BRASIL, MTO (2017)

Toda ação do Governo está estruturada em programas orientados para a realização dos objetivos estratégicos definidos para o período do PPA, ou seja, quatro anos.

Para classificar uma despesa quanto à sua natureza deve-se considerar a categoria econômica, o grupo a que pertence, a modalidade da aplicação e o elemento.

A modalidade de aplicação destina-se a indicar se os recursos serão aplicados diretamente pela unidade detentora do crédito orçamentário, ou transferidos, ainda que na forma de descentralização, a outras esferas de governo, órgãos ou entidades. BRASIL, MTO (2017)

\subsection{Vinculação de Receita no processo vinculativo brasileiro}

O constituinte de 1988 adotou, em sede doutrinária, a teoria jurídica dos tributos vinculados e não-vinculados a uma atuação estatal para operar a resolução do problema da repartição das competências tributárias.

A lei será sempre o ponto de partida para a análise da constitucionalidade das contribuições interventivas, uma vez que é o legislador quem define - na construção do fato gerador do tributo - qual será a natureza da espécie tributária a ser criada. Reportamo-nos, mais uma vez, à lição de Ataliba (2001):

Quando, pois, indagamos se a hipótese de incidência de um tributo (a) consiste ou (b) não numa atividade estatal, estamos desempenhando tarefa jurídica; estamos buscando situá-lo numa destas duas categorias: tributo (a) vinculado ou (b) não vinculado. $E$, na lei - e só nela - está a consistência da hipótese de incidência. 
Segundo Buchanan (1963), o financiamento de serviço público por um fundo geral somente permite ao cidadão que este voto no nível agregado de serviço público, enquanto a vinculação permite que o eleitor-contribuinte possa fazer "escolha" privadas sobre cada serviço público, separadamente, pela comparação de seus custos e benefícios; ou seja, há um voto separado em um imposto especifico para financiar uma referida despesa.

Segundo Froyen (2001), em um contexto de análise da escolha pública, os formuladores de políticas macroeconômicas agem de forma a maximizar seu próprio bem-estar ou utilidade e não necessariamente o bem-estar social, o que por si só renegaria os predicados de benevolência e boas intenções, de forma a maximizar, portanto, algo de seu interesse direto.

Com base nessas considerações acerca da adoção de políticas baseadas em regras fixas para os formuladores de políticas econômicas, Brennan e Buchanan propõem, além da regra de orçamento equilibrado, o modelo do "leviatã restritivo" (o Estado, como soberano absoluto e com poder sobre seus súditos que assim o autorizam através do pacto social), para legitimar a adoção de vinculações de receitas no orçamento federal, sugerindo que limites constitucionais são necessários para que seja preservado algum sentido de reciprocidade no relacionamento entre tributos e benefícios públicos.

Sob este enfoque, Brennan e Buchanan analisam a possível seleção de instrumentos tributários como meio de induzir o governo a prover bens públicos e serviços que os contribuintes desejam. Na construção do modelo, os autores adotam a hipótese de que os bens públicos são fornecidos como proporção de receita arrecadada. O Leviatã obtém ganhos da parcela arrecadada que não se transforma em gasto público. Na ausência de qualquer restrição que force o governo a agir diferentemente, ele nada proverá de bem público que interesse aos cidadãos, apenas maximizará as receitas tributarias.

Buchanan (1963), como alguns economistas defendem que a vinculação é um bom argumento em prol da eficiência alocativa, principalmente, se implementada corretamente, para bens e serviços que funcionam mais como bens privados que bens públicos, de forma que a vinculação poderia aumentar a eficiência econômica via Princípio do Benefício.

De acordo com o Princípio do Benefício (The Benefit Principle), mesmo que 
os tributos não possam ser diretamente arrecadados, ainda assim, poder ser aplicado, com ganhos de eficiência econômica, se os usuários forem taxados indiretamente pelo consumo de referido bem. DANTAS (2008)

O Princípio do Aumento de Receita, reza que a vinculação fornece suporte político para um aumento de receita (Mc Cleary, 1989). Essa prática é comum em vincular tributos sobre cigarros ou jogos para atividades como esportes, cultura, educação e saúde. Esses argumentos, tendo em vista que a vinculação é voltada para atividades benéficas, permitem ao Governo, maior facilidade, a criação de um novo tributo perante a sociedade. DANTAS (2008)

Segundo Rajkumar, o Princípio da Revenue Enhancement não importa se há aumento do gasto no item de despesa ao qual os recursos estão vinculados. O mais importante é a percepção da sociedade com respeito à utilização das receitas vinculadas. DANTAS (2008)

O princípio da Proteção (The Proction Principle), em vários países no processo orçamentário anual proporciona uma alocação de recursos bastante enviesada com relação às preferencias da sociedade. Adicionalmente, é comum haver uma instabilidade inerente ao processo orçamentário, que resulta em significante volatilidade nos padrões de gastos ao longo do tempo. Este princípio se justifica por assegurar gastos em níveis consistentes em itens prioritários, sem a volatilidade que envolve o processo orçamentário, e por garantir que o governo cumpra suas despesas obrigatórias. DANTAS (2008).

Para Albuquerque, Medeiros e Silva (2008), o uso do mecanismo vinculatório evidencia a desconfiança do legislador de hoje em relação ao governante de amanhã. Assim, se por um lado a prática busca garantir que determinadas prioridades sejam atendidas pelos governantes, por outro demonstra que a sociedade brasileira, representada por seus parlamentares, ainda não atingiu o grau de amadurecimento necessário para uma efetiva discussão permanente a respeito de suas prioridades.

\section{Procedimentos metodológicos}

Este capítulo trata da abordagem metodológica, caracterizando o tipo de pesquisa quanto aos fins e aos meios, apresentando o que constitui a unidade de análise, e definindo os instrumentos de coleta de dados, as variáveis analisadas e qual a técnica de análise de resultados. 
Para Richardson (1989, p. 29) "(...) método em pesquisa significa a escolha de procedimentos sistemáticos para a descrição e explicação de fenômenos". Desta forma, todo trabalho de pesquisa deve ser planejado e executado de acordo com as normas que acompanham cada método. As duas estratégias de pesquisa, em termos de aplicabilidade, podem ser chamadas de abordagem qualitativa e abordagem quantitativa, utilizando-se uma classificação bastante ampla.

De acordo com Vergara (2007), os tipos de pesquisa podem ser definidos por dois critérios básicos: quanto aos fins e quanto aos meios.

Quanto aos fins, para Vergara (2007), uma pesquisa pode ser: a) Exploratória: Que é realizada em áreas de pouco conhecimento sistematizado, assim sendo não comporta hipóteses na sua fase inicial, porém no decorrer da pesquisa estas poderão surgir naturalmente. b) Descritiva: É aquela que expõe características claras e bem delineadas de determinada população ou fenômeno, para isso envolve técnicas padronizadas e bem estruturadas de coletas de seus dados. c) Explicativa: Tem como principal objetivo tornar as ações estudadas em dados de fácil compreensão, justificando e explicando os seus principais motivos e o "porquê" das coisas. d) Metodológica: Está associada aos caminhos, formas, maneiras e procedimentos utilizados para atingir determinado fim. e) Aplicada: Tem necessidade de resolver problemas que já existem na prática. De forma imediata ou não. f) Intervencionista: Não se satisfaz apenas na explicação do que se está sendo estudado, mas pretende interferir de alguma forma na realidade, no dia-a-dia do seu objeto de pesquisa.

Vergara (2007), afirma que quanto aos meios de investigação, uma pesquisa pode ser: a) De campo: Baseia-se pela experiência que se está sendo aplicada na investigação e é realizada exatamente no local onde são observados os fenômenos estudados. b) De laboratório: É realizada em local determinado e limitado. c) Documental: Através de análises em documentos encontrados em órgãos públicos ou privados, ou com pessoas que detenham a guarda destes documentos. d) Bibliográfica: É aquele realizado com base em material publicado em livros, jornais, revistas, sites na internet, e que sejam disponibilizados ao público em geral. e) Experimental: Investigação empírica na qual o pesquisador manipula e controla variáveis independentes e observa os resultados destas manipulações.

Nesta pesquisa, será utilizada a abordagem quantitativa, visando identificar através de uma análise da margem de discricionariedade na gestão pública no 
município de Teófilo Otoni - MG no período de 2013a 2016. Segundo Zanella (2009) a pesquisa quantitativa caracteriza-se pelo uso de instrumentos estatísticos e tem como finalidade medir as relações entre as variáveis, apresentando uma preocupação com a representatividade numérica. Quanto aos fins, será uma pesquisa descritiva e quanto aos meios de investigação será documental e bibliográfica.

No tocante aos procedimentos a pesquisa se classifica como bibliográfica, pois utilizou-se de livros e artigos científicos para embasamento teórico da análise e quanto aos dados utilizados, foram dados secundários coletados nas bases de dados do TCE/MG.

\section{Resultados e discussão dos dados coletados}

Nesse contexto de finanças públicas e orçamento público, Esse trabalho pretende fazer uma análise da margem de discricionariedade na gestão pública: estudo de caso do município de Teófilo Otoni- MG.

O presente estudo analisa o orçamento do Município de Teófilo Otoni - MG, no período de 2013 a 2016

\subsection{A execução orçamentária do Município de Teófilo Otoni em seu PPA}

\section{- Plano Plurianual 2013/ 2016}

\begin{tabular}{|c|c|c|c|c|}
\hline Receitas Município de Teófilo Otoni & 2013 & 2014 & 2015 & 2016 \\
\hline 1000.00.00 - RECEITAS CORRENTES & $237.033 .568,74$ & $280.468 .024,00$ & $321.013 .500,00$ & $317.475 .000,00$ \\
\hline 1100.00.00 - RECEITA TRIBUTÁRIA & $19.775 .874,60$ & $25.120 .000,00$ & $27.938 .000,00$ & 27.038.000,00 \\
\hline 1200.00.00 - RECEITAS DE CONTRIBUIÇÕES & $9.388 .000,00$ & $10.866 .030,00$ & $11.701 .500,00$ & $12.833 .000,00$ \\
\hline 1300.00.00 - RECEITA PATRIMONIAL & $9.019 .000,00$ & $5.149 .244,00$ & $11.427 .000,00$ & $10.984 .780,00$ \\
\hline 1600.00.00 - RECEITA DE SERVIÇOS & $2.321 .500,00$ & $7.080 .000,00$ & $4.260 .000,00$ & $4.260 .000,00$ \\
\hline 1700.00.00 - TRANSFERÊNCIAS CORRENTES & $184.461 .640,92$ & $215.975 .500,00$ & $252.111 .960,00$ & $248.543 .600,00$ \\
\hline 1900.00.00 - OUTRAS RECEITAS CORRENTES & $12.067 .553,22$ & $16.277 .250,00$ & $13.575 .040,00$ & $13.815 .620,00$ \\
\hline 2000.00.00 - RECEITAS DE CAPITAL & $23.572 .000,00$ & $102.043 .250,00$ & $118.730 .000,00$ & $98.633 .000,00$ \\
\hline 2100.00.00 - OPERAÇÕES DE CRÉDITO & $13.255 .000,00$ & $32.200 .000,00$ & $25.000 .000,00$ & $12.500 .000,00$ \\
\hline 2200.00.00 - ALIENAÇÃO DE BENS & & $10.160 .000,00$ & $3.000 .000,00$ & $4.160 .000,00$ \\
\hline 2400.00.00 - TRANSFERÊNCIAS DE CAPITAL & & $59.683 .250,00$ & $90.730 .000,00$ & $81.973 .000,00$ \\
\hline $\begin{array}{l}\text { 7000.00.00 - RECEITAS CORRENTES } \\
\text { INTRAORÇAMENTÁRIAS }\end{array}$ & & $12.963 .129,00$ & $13.728 .300,00$ & $15.991 .000,00$ \\
\hline 7200.00.00 - RECEITAS DE CONTRIBUIÇÕES & & $11.768 .052,00$ & $12.403 .300,00$ & $15.041 .000,00$ \\
\hline 7900.00.00 - OUTRAS RECEITAS CORRENTES & & $1.195 .077,00$ & $1.325 .000,00$ & $950.000,00$ \\
\hline Deduções da Receita & & $17.837 .403,00$ & $18.471 .800,00$ & 18.099.000,00 \\
\hline 92 - Restituições & & $8.000,00$ & $8.000,00$ & $8.000,00$ \\
\hline 95 - FUNDEB & & $17.188 .000,00$ & $17.694 .000,00$ & $17.274 .000,00$ \\
\hline
\end{tabular}




\begin{tabular}{|r|r|r|r|}
$14.860 .568,74$ & $641.403,00$ & $769.800,00$ & $817.000,00$ \\
$\mathbf{1 4 . 8 6 0 . 5 6 8 , 7 4}$ & $\mathbf{1 7 . 8 3 7 . 4 0 3 , 0 0}$ & $\mathbf{1 8 . 4 7 1 . 8 0 0 , 0 0}$ & $\mathbf{1 8 . 0 9 9 . 0 0 0 , 0 0}$ \\
$\mathbf{2 5 9 . 0 0 0 . 0 0 0 , 0 0}$ & $\mathbf{3 7 7 . 6 3 7 . 0 0 0 , 0 0}$ & $\mathbf{4 3 5 . 0 0 0 . 0 0 0 , 0 0}$ & $\mathbf{4 1 4 . 0 0 0 . 0 0 0 , 0 0}$ \\
\hline
\end{tabular}

Fonte: Elaborado pelos autores com base em dados do TCE-MG. Acesso 11-12-2016.

\subsubsection{Gestão do Orçamento Público 2013/2016 - por Despesa Vinculada}

\begin{tabular}{|c|c|c|c|c|c|}
\hline \multicolumn{6}{|c|}{ Despesa Município de Teófilo Otoni - MG } \\
\hline Destinação & Descrição da Fonte de Recurso & 2013 & 2014 & 2015 & 2016 \\
\hline \multirow{2}{*}{$\begin{array}{l}\text { Recursos } \\
\text { Ordinários }\end{array}$} & 00 - Recursos Ordinários & $65.023 .812,80$ & $89.337 .150,00$ & $85.663 .855,00$ & $86.660 .865,00$ \\
\hline & Subtotal & $65.023 .812,80$ & $89.337 .150,00$ & $85.663 .855,00$ & $86.660 .865,00$ \\
\hline \multirow[t]{10}{*}{ Educação } & $\begin{array}{l}01 \text { - Receitas de Impostos e de Transferências de Impostos } \\
\text { Vinculados à Educação }\end{array}$ & $10.171 .000,00$ & $13.751 .100,00$ & $14.078 .665,00$ & $13.341 .235,00$ \\
\hline & $\begin{array}{l}18 \text { - Transferências do FUNDEB para Aplicação na } \\
\text { Remuneração dos Profissionais do Magistério em Efetivo } \\
\text { Exercício na Educação Básica }\end{array}$ & $22.380 .000,00$ & $27.801 .000,00$ & $28.140 .000,00$ & $26.400 .000,00$ \\
\hline & $\begin{array}{l}19 \text { - Transferências do FUNDEB para Aplicação em Outras } \\
\text { Despesas da Educação Básica }\end{array}$ & $5.120 .000,00$ & $4.119 .000,00$ & $7.060 .000,00$ & $8.800 .000,00$ \\
\hline & 22 - Transferências de Convênios Vinculados à Educação & $2.750 .000,00$ & $3.580 .000,00$ & $7.386 .000,00$ & $5.346 .000,00$ \\
\hline & $\begin{array}{l}43 \text { - Transferências de Recursos do FNDE Referentes ao } \\
\text { Programa Dinheiro Direto na Escola (PDDE) }\end{array}$ & $30.000,00$ & $42.000,00$ & $43.000,00$ & $32.000,00$ \\
\hline & $\begin{array}{l}44 \text { - Transferências de Recursos do FNDE Referentes ao } \\
\text { Programa Nacional de Alimentação Escolar (PNAE) }\end{array}$ & $913.000,00$ & $1.103 .000,00$ & $1.289 .000,00$ & $1.489 .000,00$ \\
\hline & $\begin{array}{l}45 \text { - Transferências de Recursos do FNDE Referentes ao } \\
\text { Programa Nacional de Apoio ao Transporte Escolar (PNATE) }\end{array}$ & $726.000,00$ & $802.000,00$ & $803.000,00$ & $803.000,00$ \\
\hline & 46 - Outras Transferências de Recursos do FNDE & $7.500 .000,00$ & $9.353 .000,00$ & 22.105.780,00 & $21.311 .780,00$ \\
\hline & 47 - Transferência do Salário-Educação & $1.500 .000,00$ & $2.006 .000,00$ & $2.209 .000,00$ & $2.209 .000,00$ \\
\hline & Subtotal & $51.090 .000,00$ & $62.557 .100,00$ & 83.114.445,00 & $79.732 .015,00$ \\
\hline \multirow[t]{11}{*}{ Saúde } & $\begin{array}{l}02 \text { - Receitas de Impostos e de Transferências de Impostos } \\
\text { Vinculados à Saúde }\end{array}$ & $17.802 .390,00$ & $19.466 .000,00$ & $19.183 .520,00$ & 19.183.520,00 \\
\hline & 23 - Transferências de Convênios Vinculados à Saúde & $10.000,00$ & $2.800 .000,00$ & $13.863 .000,00$ & $2.500 .000,00$ \\
\hline & 48 - Transferências de Recursos do SUS para Atenção Básica & $1.000 .000,00$ & $11.403 .000,00$ & $14.207 .000,00$ & $16.000 .000,00$ \\
\hline & $\begin{array}{l}49 \text { - Transferências de Recursos do SUS para Atenção de } \\
\text { Média e Alta Complexidade Ambulatorial e Hospitalar }\end{array}$ & $6.050 .000,00$ & $52.970 .000,00$ & $61.762 .940,00$ & $66.280 .000,00$ \\
\hline & $\begin{array}{l}50 \text { - Transferências de Recursos do SUS para Vigilância em } \\
\text { Saúde }\end{array}$ & $49.465 .797,20$ & $955.000,00$ & $1.981 .000,00$ & $1.590 .000,00$ \\
\hline & $\begin{array}{l}51 \text { - Transferências de Recursos do SUS para Assistência } \\
\text { Farmacêutica }\end{array}$ & $1.372 .000,00$ & $816.000,00$ & $854.800,00$ & $895.000,00$ \\
\hline & 52 - Transferências de Recursos do SUS para Gestão do SUS & $860.000,00$ & & $115.900,00$ & $60.000,00$ \\
\hline & $\begin{array}{l}53 \text { - Transferências de Recursos do SUS para Investimentos na } \\
\text { Rede de Serviços de Saúde }\end{array}$ & $255.000,00$ & $10.420 .000,00$ & $10.483 .060,00$ & $9.460 .000,00$ \\
\hline & 54 - Outras Transferências de Recursos do SUS & $55.000,00$ & & $119.680,00$ & $50.000,00$ \\
\hline & 55 - Transferências de Recursos do Fundo Estadual de Saúde & $255.000,00$ & $16.410 .100,00$ & $20.334 .800,00$ & $18.330 .000,00$ \\
\hline & Subtotal & $81.375 .187,20$ & $115.240 .100,00$ & $142.905 .700,00$ & $134.348 .520,00$ \\
\hline \multirow[t]{4}{*}{ Assistência } & $\begin{array}{l}29 \text { - Transferências de Recursos do Fundo Nacional de } \\
\text { Assistência Social (FNAS) }\end{array}$ & $3.436 .000,00$ & $4.150 .000,00$ & $4.150 .000,00$ & $3.781 .960,00$ \\
\hline & $\begin{array}{l}42 \text { - Transferências de Convênios Vinculados à Assistência } \\
\text { Social }\end{array}$ & $1.700 .000,00$ & $527.000,00$ & $528.000,00$ & $528.000,00$ \\
\hline & $\begin{array}{l}56 \text { - Transferências de Recursos do Fundo Estadual de } \\
\text { Assistência Social (FEAS) }\end{array}$ & $780.000,00$ & $1.755 .000,00$ & $1.750 .000,00$ & $1.687 .640,00$ \\
\hline & Subtotal & $5.916 .000,00$ & $6.432 .000,00$ & $6.428 .000,00$ & $5.997 .600,00$ \\
\hline \multirow[t]{4}{*}{$\begin{array}{l}\text { Outros } \\
\text { Recursos } \\
\text { Vinculados }\end{array}$} & $\begin{array}{l}03 \text { - Contribuição para o Regime Próprio de Previdência Social } \\
\text { (RPPS): Patronal, dos Servidores, Compensação Financeira }\end{array}$ & $24.997 .000,00$ & $20.999 .000,00$ & $27.000 .000,00$ & $30.000 .000,00$ \\
\hline & $\begin{array}{l}17 \text { - Contribuição para Custeio dos Serviços de lluminação } \\
\text { Pública (COSIP) }\end{array}$ & $351.000,00$ & $5.500 .000,00$ & $6.000 .000,00$ & $1.000,00$ \\
\hline & $\begin{array}{l}24 \text { - Transferências de Convênios Não Relacionados à } \\
\text { Educação, à Saúde nem à Assistência Social }\end{array}$ & $4.500 .000,00$ & $34.511 .650,00$ & $54.652 .000,00$ & $6.600 .000,00$ \\
\hline & 57 - Multas de Trânsito & $19.210 .000,00$ & $700.000,00$ & $1.236 .000,00$ & $53.400 .000,00$ \\
\hline
\end{tabular}




\begin{tabular}{|l|r|r|r|r|}
\hline 90 - Operações de Crédito Internas & $1.485 .000,00$ & $32.200 .000,00$ & $25.000 .000,00$ \\
\hline 92 - Alienação de Bens & $4.851 .000,00$ & $10.160 .000,00$ & $3.000 .000,00$ & $12.500 .000,00$ \\
\hline Subtotal & $\mathbf{5 5 . 5 9 5 . 0 0 0 , 0 0}$ & $\mathbf{1 0 4 . 0 7 0 . 6 5 0 , 0 0}$ & $\mathbf{1 1 6 . 8 8 8 . 0 0 0 , 0 0}$ & $\mathbf{1 0 7 . 2 6 1 . 0 0 0 , 0 0}$ \\
\hline Total & $\mathbf{2 5 9 . 0 0 0 . 0 0 0 , 0 0}$ & $\mathbf{3 7 7 . 6 3 7 . 0 0 0 , 0 0}$ & $\mathbf{4 3 5 . 0 0 0 . 0 0 0 , 0 0}$ & $\mathbf{4 1 4 . 0 0 0 . 0 0 0 , 0 0}$ \\
\hline
\end{tabular}

Fonte: Elaborado pelos autores com base em dados do TCE-MG. Acesso 11-12-2016.

4.2 Análise do Desempenho do Município - Saúde: No Processo Vinculativo das Despesa com Saúde Total/ Receita Corrente Líquida: Considera-se o total das despesas com saúde e, de acordo com a LRF o limite mínimo de 15\% deve ser obedecido.

\subsection{1 ndice de Gasto com Saúde do Município de Teófilo Otoni - MG}

\begin{tabular}{lrrrr}
\multicolumn{5}{c}{ ÍNDICE DE GASTO COM SAÚDE DO MUNICÍPIO DE TEÓFILO OTONI } \\
& $\mathbf{2 0 1 3}$ & $\mathbf{2 0 1 4}$ & $\mathbf{2 0 1 5}$ & \multicolumn{1}{c}{$\mathbf{2 0 1 6}$} \\
\hline DESPESA COM SAÚDE & $81.375 .187,20$ & $115.240 .100,00$ & $142.905 .700,00$ & $134.348 .520,00$ \\
RECEITA CORRENTE LIQUIDA & $237.033 .568,74$ & $280.468 .024,00$ & $321.013 .500,00$ & $317.475 .000,00$ \\
\hline IGP & 0,34 & 0,41 & 0,45 & 0,42 \\
$\%$ & 34,33 & 41,09 & 44,52 & 42,32
\end{tabular}

De acordo com o índice, a despesa com saúde no período foi superior aos $15 \%$ estipulado na LRF. Garantindo assim as transferências e repasses da União e do Estado. Os índices apresentados ficaram bem acima do estabelecido em lei.

4.3 Despesa com Educação Total/ Receita Corrente Líquida: considera-se o total das despesas com Educação e, de acordo com a LRF. A Constituição exige que os municípios apliquem ao menos $25 \%$ de sua receita resultante de impostos e transferências na manutenção e no desenvolvimento da Educação. A lei é a mesma para os estados e, no caso da União o percentual mínimo é de 18\%.

\subsection{1 Índice de Gasto com Educação do Município de Teófilo Otoni - MG}

\begin{tabular}{|c|c|c|c|c|}
\hline \multicolumn{5}{|c|}{ ÍNDICE DE GASTO COM EDUCAÇÃODO MUNICÍPIO DE TEÓFILO OTONI } \\
\hline & 2013 & 2014 & 2015 & 2016 \\
\hline DESPESA COM EDUCAÇÃO & $51.090 .000,00$ & $62.557 .100,00$ & $83.114 .445,00$ & 79.732.015,00 \\
\hline RECEITA CORRENTE LIQUIDA & $237.033 .568,74$ & $280.468 .024,00$ & $321.013 .500,00$ & $317.475 .000,00$ \\
\hline IGP & 0,22 & 0,22 & 0,26 & 0,25 \\
\hline$\%$ & 21,55 & 22,30 & 25,89 & 25,11 \\
\hline
\end{tabular}

De acordo com o índice, a despesa com educação nos anos de 2013 e 2014 não atenderam ao mínimo estabelecido de $25 \%$ estipulado na LRF. Comprometendo assim as transferências voluntárias, de contratação de crédito e a concessão de 
garantias para a obtenção de empréstimos. Já nos anos seguintes estes índices foram atendidos

\subsection{Gastos com Pessoal (IGP)}

Despesa com Pessoal Total/ Receita Corrente Líquida: considera-se o total das despesas com pessoal e, de acordo com a LRF.Nos Municípios, os limites máximos para gastos com pessoal (60\% da Receita Corrente Líquida) serão:

$\checkmark$ 6\% para o Legislativo, incluindo o Tribunal de Contas

$\checkmark 54 \%$ para o Executivo

\begin{tabular}{lrrrr}
\multicolumn{5}{c}{ ÍNDICE DE GASTO COM PESSOAL DO MUNICÍPIO DE TÉOFILO OTONI } \\
& $\mathbf{2 0 1 3}$ & $\mathbf{2 0 1 4}$ & $\mathbf{2 0 1 5}$ & \multicolumn{2}{c}{$\mathbf{2 0 1 6}$} \\
\hline DESPESA COM PESSOAL & $100.197 .445,22$ & $113.925 .250,57$ & $133.121 .206,27$ & $153.762 .533,41$ \\
RECEITA CORRENTE LIQUIDA & $237.033 .568,74$ & $280.468 .024,00$ & $321.013 .500,00$ & $317.475 .000,00$ \\
\hline IGP & 0,42 & 0,41 & 0,41 & 0,48
\end{tabular}

Fonte: https://fiscalizandocomtce.tce.mg.gov.br

De acordo com o índice, a despesa com pessoal não excedeu os $60 \%$ estipulado na LRF. Garantindo assim as transferências voluntárias, de contratação de crédito e a concessão de garantias para a obtenção de empréstimos.

\section{Considerações finais}

Esse trabalho teve como objetivo fazer uma análise da margem de discricionariedade no orçamento do município de Teófilo Otoni- MG. A análise compreende o orçamento desse Município no período de 2013 a 2016.

É importante ressaltar que no contexto federativo brasileiro, conhecer a disponibilidade de recursos financeiros e o perfil das despesas dos municípios é de fundamental relevância para identificação de problemas e levantamento de soluções que integrem a atuação dos poderes municipais, estaduais, federal. Isto é igualmente importante para sociedade. É uma forma de oportunizar a conscientização fiscal, subsidiar o controle social e promover o exercício da cidadania, face aos instrumentos de planejamento e gestão social.

O resultado da pesquisa apresenta a vinculação das receitas e despesas do Município de Teófilo Otoni. Os investimentos com a saúde chegaram a representar $44,53 \%$ do total da Receita Corrente Líquida. Ficando claro que atendeu os limites estabelecidos na Lei de responsabilidade Fiscal, ao qual corresponde à 15\%. 
Segundo o estudo, a despesa vinculada com a educação, não atendeu o percentual obrigatório de $25 \%$ entre os anos de 2013 a 2014 e atendeu o percentual obrigatório nos anos de 2015 e 2016. Os gastos com a educação representaram em média cerca de $24 \%$ da Receita Corrente Líquida dentro do período analisado.

A partir dos dados coletados e analisados, a vinculação das receitas e despesas do orçamento no município de Teófilo Otoni entre os anos de 2013 a 2016 totalizaram quase $70 \%$ da Receita Corrente líquida desse Município. O percentual restante, que possibilita o investimento de forma discricionária foi de aproximadamente $30 \%$ da Receita Corrente Líquida. Com o valor restante, o gestor público pôde investir em políticas públicas que abarcam as demais funções do Município.

Com base nos resultados analisados anteriormente das receitas e despesas vinculadas do município de Teófilo Otoni, pode-se considerar que a margem de discricionariedade do gestor público é bem pequena. $O$ recurso que fica a critério do mesmo para que seja investido em outras políticas públicas, que não sejam de receitas vinculadas representa $30 \%$ da $R C L$.

Percebe-se que os valores investidos em educação e saúde são consideráveis quando se compara $\mathrm{RCL}$ do Município. O que pressupõe que para uma cidade com cerca de 135 mil habitantes, o que se refere a saúde e educação estariam atendendo as demandas da sociedade com efetividade. Mas será que estão? Questionamento que também precisa ser investigado.

É necessário que para além do montante financeiro investido, deve-se analisar como esses recursos discricionários ou não- discricionários estão sendo gastos, quais políticas públicas tem sido promovidas não só na saúde e educação, mas em todas as demais funções do governo, que possam justificar despesas milionárias conforme as apresentadas nesse estudo, são extremamente importantes.

Acredita-se que a vinculação garante ao cidadão que o recurso será aplicado em seu benefício. De fato a adoção de políticas baseadas em regras fixas para os formuladores de políticas econômicas, segundo Brennan e Buchanan propõem, que além da regra de orçamento equilibrado, o modelo do "leviatã restritivo" (o Estado, como soberano absoluto e com poder sobre seus súditos que assim o autorizam através do pacto social), para legitimar a adoção de vinculações de receitas no orçamento federal, sugerindo que limites constitucionais são necessários para que seja preservado algum sentido de reciprocidade no 
relacionamento entre tributos e benefícios públicos.

\section{Referências}

ALBUQUERQUE, Claudiano Manoel de; MEDEIROS, Márcio Bastos; SILVA, Paulo Henrique Feijó da. Gestão de Finanças Públicas: fundamentos e práticas de planejamento, orçamento e administração financeira com responsabilidade fiscal. Brasília: Ed. do autor, 2008.

ANJOS, Pedro G., Os Graus da Discricionariedade da Administração Pública no Âmbito do Direito Orçamentário. Disponível em:

http://www.publicadireito.com.br/conpedi/manaus/arquivos/anais/brasilia/12_42.pdf . Acesso em: 12 de dezembro de 2017.

ATALIBA, Geraldo. Hipótese de incidência tributária. 5. ed. São Paulo: Malheiros, 1996.

ATALIBA, Geraldo. Hipótese de Incidência Tributária. São Paulo: Malheiros, 2001, pp. $130-2$

Brasil, Constituição da República Deferativa do Brasil (1988). Disponível em :http://www.planalto.gov.br/ccivil03/constuição. Acesso em: 06 de Novembro de 2017.

,Lei 4.320, de 17 de Março de 1964. Disponivel:

http://www.planalto.gov.br/ccivil_03/leis/L4320.htm, Acesso: 05/11/2017

Lei Complementar número 101, de 04 de Maio de 2.000. Disponivel: www.planalto.gov.br/ccivil_03/leis/LCP/Lcp101.htm, Acesso: 05 de novembro de 2017.

,Lei № 5.172, de 25 de outubro de 1966. Disponível:

www.planalto.gov.br/ccivil_03/leis/L5172.htm, Acesso: 06/11/2017

, Decreto no 93.872, de 24 de dezembro de 1986. Disponível:

www.planalto.gov.br/ccivil_03/decreto/d93872.htm, Acesso: 07 de novembro de 2017.

Ministério do Planejamento, Desenvolvimento e Gestão. Secretaria de

Orçamento Federal. - Manual Técnico de Orçamento. Disponível:

http://www.planejamento.gov.br/assuntos/orcamento-1/informacoes-

orcamentarias/arquivos/MTOs/manual-tecnico-de-orcamento-3a-versao.pdf,

Edição 2017.Brasília, 2016. Acesso: 07 de novembro de 2017.

BÖS, D. Earmarked Taxation: Welfare versus Political Support. Journal of Public Economics, v.75, 2000. 
BUCHANAN, J. M. The Economics of Earmarked Taxes. The Journal of Political Economy, v. 71, no 5 , out. 1963.

DANTAS, K. E. G. A Vinculação de Receita Pós-Constituição Federal de 1988: rigidez ou flexibilidade da política fiscal? O caso da Cide-Combustíveis. In: Revista finanças Públicas - XIV Prêmio Tesouro Nacional - 2009.

QUINTANA, Alexandre C; MACHADO, Daiane P.; Quaresma, Jozi C. da C.; MENDES, Roselaine da C. Contabilidade Pública: de acordo com as Novas Normas Brasileiras de Contabilidade aplicadas ao setor público e ao Lei de Responsabilidade Fiscal. São Paulo: Atlas, 2011.

REIS, P. R. da C.; COSTA, T. de M. T. da; SILVEIRA, S. de F. R.. Receita pública e bem-estar social nos municípios mineiros emancipados no período de 1988 a 1997. READ. Revista eletrônica de administração, PortoAlegre, v. 19, n. 1, p. 6182, abr. 2013 . Disponível em:

<http://www.scielo.br/scielo.php?script=sci_arttext\&pid=S1413-

$23112013000100003 \&$ Ing=en\&nrm=iso >. Acesso em: 27 mar. 2017.

REZENDE, F. A. Finanças Públicas. 2. ed. São Paulo: Atlas, 2006.

RICHATO, Adriana L.B. F. A Desvinculação de Receitas de Estados e Municípios (DREM), Consultora Contábil do IGAM, 28 de junho de 2017 Disponível, em: www.igam.com.br/gestaopublica/a-desvinculacao-de-receitas-de-estados-emunicipios-drem , acesso em : 13-12-17

SOSTMEIER, P. Planejamento e Aplicação do Orçamento no Governo Municipal, Sapiranga /RS, 2012.

Disponivel: https://www.lume.ufrgs.br/bitstream/handle/10183/71505/000874597.pdf , Acesso: 17/04/2017

SOUZA, C. Governos locais e gestão de políticas sociais universais. São Paulo em Perspectiva, 18 p. 27-41, 2004. Disponível em: < http://www.scielo.br/pdf/spp/v18n2/a04v18n2.pdf>. Acesso em: 29. abr. 2017.

TOMIO, F. R. de L. A criação de municípios após a Constituição de 1988. Revista brasileira de Ciências Sociais, SãoPaulo, v. 17, n. 48, p. 61-

89, fev. 2002 .Disponível

em:http://www.scielo.br/pdf/rbcsoc/v17n48/13950.pdf>.Acesso em: 17. mar. 2017.

TOMIO, F.de L; ORTOLAN, M. Federalismo Predatório e Municipalização de Políticas Públicas Sociais. RAM- Revista de Administração Municipal. Rio de Janeiro, n. 284, p. 4-14, dez. 2015.

TORRES , Macelo Douglas F., Fundamentos de Administração Pública

Brasileira, 1 ed. Rio de Janeiro, Editora: FGV, 2012. ISBN: 9788522512324

VERGARA, Sylvia Constant. Projetos e relatórios de pesquisa em administração. 9 ed. São Paulo: Atlas, 2007. 
YIN, Robert K. Estudo de caso: planejamento e método. 2. ed. Porto Alegre: Brookman, 2001. 